\title{
Hamlet acabará Narciso? Associação Brasileira de Escritores 1941-1945
}

\author{
Hamlet eventually Narcissus? Associação Brasileira de \\ Escritores 1941-1945
}

\section{Ana Paula Palamartchuk ${ }^{1}$}

RESUMO

Este artigo tem como objetivo pensar a criação da Sociedade Brasileira de Escritores, em São Paulo, em 1942 e sua transformação em Associação Brasileira de Escritores, no mesmo ano. A partir de então, com sede no Rio de Janeiro, várias seções estaduais foram sendo criadas. Funcionando em pleno Estado Novo, só realizou seu primeiro Congresso Nacional, em São Paulo, em janeiro de 1945, mesmo assim com pouquíssima cobertura da grande imprensa. Foi considerado um dos eventos mais importantes contra o Estado Novo e conseguiu reunir nomes importantes e consagrados do mundo editorial nacional. Assim, a proposta é recuperar a trajetória dessa efêmera organização de escritores, assim como os sujeitos ai envolvidos e os projetos em disputa.

Palavras-chave: Intelectuais; Política; Cultura; Getúlio Vargas; Estado Novo; História; História do Brasil.

\section{ABSTRACT}

This article aims to reflect the creation of the Brazilian Society of Writers, in São Paulo in 1942 and its transformation into the Brazilian Association of Writers in the same year. Thereafter, based in Rio de Janeiro, various state sections were created. Running on the Estado Novo period, only held its first National Congress in São Paulo, in January 1945, still with very little mainstream media coverage. Was considered one of the most important events against the Estado Novo and gathered important names in the world and consecrated national publishing. The proposal is to recover the trajectory of this ephemeral organization of writers, as well as the subjects involved there and competing projects.

Keyword: Intellectuals; Politics; Culture; Getulio Vargas; Estado Novo; History; History of Brazil.

1 Doutora em História pela Universidade Estadual de Campinas (UNICAMP). Professora Adjunta dos cursos de licenciatura e bacharelado em História, e do Programa de Pós-Graduação em História - Universidade Federal de Alagoas UFAL. 
No dia 19 de janeiro de 1945, uma sexta-feira, desembarcava do trem "Cruzeiro do Sul" em São Paulo, vindo do Rio de Janeiro, o escritor mineiro Aníbal Machado2. Presidente da Associação Brasileira de Escritores (ABDE), o escritor chegava à paulicéia para os últimos preparativos do I Congresso Brasileiro de Escritores.

Naquele dia, os jornais entusiasticamente anunciavam que as tropas russas avançavam na Alemanha, já tendo ocupado algumas cidades na Silésia. A cada dia, desde a libertação da França do domínio alemão em junho de 1944, o fim da guerra parecia mais próximo.

As motivações dos organizadores do congresso centravam-se no fim da guerra, na vitória do Aliados e no esgotamento político do Estado Novo. Neste clima, realizou-se a última reunião da comissão organizadora antes do congresso, para o qual eram esperados mais de 250 delegados de vários estados do país e convidados estrangeiros. Fizeram parte da comissão, além do presidente, Sérgio Milliet (presidente da seção paulista), assim como toda a sua diretoria, Dionélio Machado (presidente da seção gaúcha), Murilo Rubião (presidente da seção mineira) e Jorge Amado (presidente da seção baiana)3.

Outras motivações para a realização do I Congresso, essas de caráter profissional, tinham já alguma história. Algumas delas centravam-se no debate desde meados dos anos trinta e transitavam entre o papel social do autor e o mercado editorial, entre a indústria gráfica e o público, em um contexto no qual o corporativismo ia paulatinamente se tornando central nos discursos e ações do Governo Vargas.

Nesse debate, aspectos políticos, que dialogam com aspectos éticos, eram expressões da atribuição da função "civilizadora" do escritor, ao mesmo tempo em que eram minados pela intervenção despolitizadora e homogeneizante do mesmo Governo Vargas.

2 Aníbal Monteiro Machado nasceu em Sabará (MG), a 9 de dezembro de 1894. Em 1919, foi nomeado promotor público na cidade de Airuoca (MG). Em 1921, tornou-se professor de História Universal no consagrado Colégio Mineiro de Belo Horizonte. Ainda com certo resguardo, participou do "modernismo" publicando artigos em diversas revistas ligadas ao movimento. Desde então, foi um colaborador assíduo na imprensa brasileira. Em 1923, foi para o Rio de Janeiro e, depois de uma rápida passagem como delegado de polícia, tornou-se catedrático de Literatura no Colégio Pedro II. Durante a década de 1930, passou por vários empregos: no Ministério da Justiça, professor de literatura em diversos colégios particulares, voltando posteriormente para a Justiça. Foi eleito presidente da ABDE em 1944.

3 Sérgio Milliet da Costa e Silva nasceu em São Paulo em 1898, filho de um comerciante de ferragens e uma francesa. Terminou o ginásio na Suíça e freqüentou a Seção de Ciências Econômicas e Sociais na Universidade de Berna. Ao regressar ao Brasil participa da Semana de Arte Moderna. Entre uma viagem ou outra à Europa e a publicação de mais um livro, Milliet viveu os anos vinte. Em 1935, passou a dirigir a Divisão de Documentação Histórica da Pref. Mun. de São Paulo. Contribuiu com diversos jornais e revistas de cultura do Rio e de São Paulo.

Dyonelio Tubino Machado nasceu em Quaraí (RS) em 1895. Formou-se pela Faculdade de Medicina do RS, especializandose em Psiquiatria. Foi presidente da Aliança Nacional Libertadora-RS em 1935, ficando preso durante vários meses, fato que provocou na grande imprensa do Rio e de São Paulo, várias manifestações exigindo sua liberdade. Escreveu Os ratos também em 1935, sendo agraciado com o Prêmio Machado de Assis da Acad. Bras. de Letras.

Murilo Rubião nasceu em Silvestre Ferraz em 1916. Participou de diversos jornais, tornando-se um reconhecido jornalista mineiro, atuante também na rádio Inconfidência Mineira. Sua estréia literária só se deu em 1947 quando publicou o livro de contos Os ex-mágicos. 
Em meio a essa tensão, surge a Sociedade Brasileira dos Escritores em São Paulo, em 14 de março de 1942. A semana de arte moderna completava o seu $20^{\circ}$ aniversário e os intelectuais de São Paulo faziam referência ao "espírito vanguardista e modernizante da cultura bandeirante", na qual o mercado editorial já era uma realidade. Na sua fundação não houve festas nem comemorações, o Estado Novo não permitia.

No Rio, o grupo que editava a revista Diretrizes saudou a iniciativa e logo propôs levar a Sociedade para a capital do país (LAHUERTA, 1992, p. 305-308). O que aconteceu de fato alguns meses depois, quando a revista publicou a Declaração de Princípios da nova entidade, em junho de 1942:

A guerra atual nada mais é que o choque histórico decisivo entre as forças progressistas que visam ampliar e consolidar as liberdades democráticas, e as forças retrógradas empenhadas em manter e alargar no mundo inteiro os regimes de escravidão e opressão./ A tradição invariável da política externa do Brasil tem sido no sentido de solidariedade e apoio aos países que lutam pela sua liberdade e independência. Dentro mesmo de nossas fronteiras lutamos sempre pelas liberdades democráticas. Assim foi nos tempos coloniais, no período da Independência, na Regência, no II Reinado e na República. Nossa posição atual de unidade panamericana na repulsa ao fascismo obedece, por isso mesmo, aos imperativos de nossa tradição histórica, da qual não é possível fugir sem contrariar o próprio sentido de nossa formação./ A Nação Brasileira assumiu em face da guerra a posição reclamada pela quase totalidade de seus filhos. (DIRETRIZES, 1942). ${ }^{4}$

Um grupo bastante heterogêneo, tanto do ponto de vista político, da produção literária, como do lugar social que ocupavam, assinava a Declaração: profissionais que articularam as principais revistas especializadas em literatura e "cultura" permitidas pela censura, escritores e intelectuais que ocupavam cargos públicos, jovens que acabavam de publicar seus primeiros trabalhos, médicos, advogados, novelistas, poetas, artistas plásticos, etc. Não

\footnotetext{
4 Assinaram a Declaração: Abelardo da Fonseca, Abelardo Romero, Abgar Renault, Afonso Arinos de Melo Franco, Afonso Varzea, Aydano do Couto Ferraz, Alceu Marinho Rego, Álvaro Lins, Álvaro Moreyra, Alvarus, Amando Fontes, Angione Costa, Anibal Machado, Aparicio Torelly, Arthur Ramos, Astrojildo Pereira, Augusto Meyer, Augusto Rodrigues, Arquimedes de Melo Neto, Aurélio Buarque de Holanda, Austregesilo de Athayde, Candido Portinari, Carlos Drummond de Andrade, Carlos Lacerda, Carlos Pontes, Costa Rego, Clovis Gusmão, Clovis Ramalhete, Dalcidio Jurandir, Dante Milano, Dias da Costa, Edison Carneiro, Emil Farhat, Esmaragdo de Freitas, Evaristo de Moraes Filho, Francisco de Assis Barbosa, Francisco Karam, Francisco Venancio Filho, Frederico Barata, Gastão Cruis, Genolino Amado, Graciliano Ramos, Guilherme Figueiredo, Hermes Lima, Homero Pires, Ivan Lins, Jayme Adour da Camâra, Jayme de Barros, Joaquim Cardoso, Jocelyn Santos, Joel Silveira, José Augusto, José Candido de Carvalho, José Cesar Borba, José Honorio Rodrigues, José Lins do Rego, Josué de Castro, Julio Paternostro, Leônidas de Rezende, Cheretine, Lindolfo Collor, Lucia Miguel Pereira, Luiz Jardim, Manuel Bandeira, Mauricio Goulart, Miguel Osorio de Almeida, Moacyr de Abreu, Moacyr Werneck, Modestino Kanto, Moesia Rolim, Mucio Leão, Murilo Mendes, Odylo Costa Filho, Orris Soares, Oscar Niemeyer, Orlando Dantas, Osorio Borba, Oswaldo Alves, Otávio Tarquinio de Souza, Paulo Medeiros e Albuquerque, Paulo Werneck, Pedro Nava, Peregrino Jr., Procópio Ferreira, Prudente de Moraes Neto, Rachel de Queiroz, Rodrigo M. F. de Andrade, Rodrigo Otavio Filho, Roquette Pinto, Rubem Braga, Samuel Wainer, Santa Rosa, Sérgio Buarque de Holanda, Teofilo de Andrade, Vianna Moog, Virgilio de Melo Franco, Vitor Espírito Santo, Vivaldo Coaracy.
} 
havia referência à Sociedade Brasileira de Escritores ou a ABDE, mas havia a expectativa comum de que a posição do Brasil na guerra fosse ao lado dos Aliados. Anos mais tarde, a revista Literatura, dirigida por Astrojildo Pereira, no seu $n^{\circ} 4$ (junho/1947), reproduziu a Declaração como "uma das primeiras manifestações da organização dos escritores na luta pela democracia e contra o fascismo". (MANIFESTO, $\mathrm{n}^{\circ} 4$, junho de 1947).

A ABDE seria então fundada em 1942, com sede no Rio de Janeiro, ocupando uma das salas da sede da Associação Brasileira de Imprensa ${ }^{5}$. Na reunião de fundação, estiveram presentes 25 escritores de vários Estados do país, entre os quais: Graciliano Ramos, Francisco de Assis Barbosa, Otávio Tarquinio de Souza, Vinicius de Moraes, Carlos Drummond de Andrade, Astrojildo Pereira, Aurélio Buarque de Holanda, Tito Batini, Josué Montello, Marques Rebelo, Manuel Bandeira, Álvaro Lins, Dante Costa, Rodrigo Melo Franco de Andrade e José Lins Rego. (COLEÇÃO FOTOGRAFICA, 1942, Foto n.1,4).

A Declaração dos escritores não fora uma manifestação isolada. O rompimento do Brasil com o Eixo acabou acontecendo em janeiro de 1942. Mas a declaração de guerra aos países do Eixo só aconteceu em agosto, depois de serem torpedeados seis navios brasileiros na costa nordestina por submarinos alemães, custando a vida de 550 pessoas. Ao declarar-se em guerra, o governo brasileiro começou a organizar a Força Expedicionária Brasileira e tomou medidas de represálias contra alemães e italianos que viviam no Brasil, congelando suas contas bancárias e proibindo que falassem seu idioma em lugares públicos. A campanha deu resultados. Um exemplo foi o ofício recebido pelo DIP da Sociedade Brasileira de Autores Teatrais (SBAT), no qual comunicava a decisão da diretoria para que fossem evitadas as representações de peças de autores alemães, italianos, húngaros, romenos, japoneses e finlandeses. A resposta do DIP ao ofício revela o espírito de xenofobia e anti-semitismo do governo: "A medida revela o espírito patriótico que norteia essa Sociedade e merece os aplausos deste Departamento. Atenciosamente, Major Antônio José Coelho dos Reis." (AGENCIA NACIONAL, DG-645).

Espírito que encontrou ressonância nas manifestações vistas em São Paulo com repúdio, anos depois, pela filha de imigrantes italianos Zélia Gattai, nas quais as lojas de comércio e escritórios alemães e italianos eram saqueados e, às vezes, incendiados. (GATTAI, 1982, p. 25-27).

A ousadia da publicação da Declaração de Princípios, além do conteúdo crítico ao Estado Novo, era a assinatura dos escritores e intelectuais, já que muitos se encontravam presos ou exilados por divergência com a política de Vargas.

5 Não podemos deixar de ressaltar o papel da ABI neste momento. Havia a seção de imprensa junto ao DIP, cujas atribuições eram, entre outras, organizar a propaganda do governo na imprensa nacional e fazer a censura de todas as empresas jornalísticas, assim como definir o que era permitido e o que não era permitido circular na imprensa. Essas atribuições eram coordenadas e controladas pelo Conselho Nacional de Imprensa (criado pouco depois do DIP). Faziam parte desse conselho 6 membros, 3 nomeados pelo presidente da República e os demais eram indicados pela ABI e pelo Sindicato de Proprietários de Jornais e Revistas do Rio de Janeiro. 
Alguns exilados, com a declaração de guerra ao eixo, decidiram voltar ao país. Este foi o caso de Pedro Mota Lima, Jorge Amado e Fernando Lacerda que vieram do Rio da Prata em direção a São Paulo e Rio de Janeiro. Mota Lima foi preso na Associação Brasileira de Imprensa no Rio, Amado e Lacerda conseguiram escapar, mas por pouco tempo. Os escritores de oposição e de esquerda que não se encontravam presos ou exilados, circulavam com certa discrição pelos periódicos legais.

A revista Cultura Política, criada em 1939 sob a batuta do DIP e diretamente ligada ao Ministro da Educação, Gustavo Capanema, foi um desses espaços. Escreveram na revista colaboradores do governo Vargas como, por exemplo, Francisco Campos (redator da Constituição de 1937), o jornalista carioca Azevedo Amaral, o sergipano Lourival Fontes (futuro diretor do DIP), Gilberto Freyre e outros. Graciliano Ramos, que acabava de deixar o cárcere, onde permaneceu durante quase dois anos sem processo contra ele instaurado, também se encontrava entre os colaboradores da revista governista.

A revista carioca Diretrizes dirigida por Samuel Wainer, foi outro ponto de encontro entre diferentes grupos de escritores. Em seu conselho de redação constava artigos de Jorge Amado, Otávio Malta, Osório Borba, Rubem Braga, Álvaro Moreira, Joel Silveira, Francisco de Assis Barbosa, Aparício Torelli e Graciliano Ramos. Azevedo Amaral emprestou o nome para o expediente no lugar do diretor e conseguiu para o amigo Wainer vários anunciantes para a revista, entre eles a Light.

Jorge Amado era procurado pela policia-política e tinha alguns de seus livros proibidos; Graciliano Ramos acabara de sair da prisão, denunciado como "comunista", mas escrevia em Cultura Política; Joel Silveira e Aparício Torelli eram perseguidos pela policia-política como “comunistas"; Álvaro Moreira foi fichado pelo DEOPS-SP como "escritor comunista".

Mas a estratégia para aproximar vários intelectuais do governo de Vargas não se restringia às colaborações para a revista do DIP e nas "facilidades" concedidas às revistas como no caso de Diretrizes, que perde tais facilidades em $1943^{6}$. (AGENCIA NACIONAL, DG512) Houve também a contratação de intelectuais em cargos do governo. $O$ chefe de gabinete de Gustavo Capanema era Carlos Drummond de Andrade ${ }^{7}$. (Gabinete Civil da Presidência da República/NA) Amigo do ministro desde a adolescência, ele pedira demissão do cargo em março de 1936 por divergências com os católicos que, segundo Drummond, abarrotavam o Departamento de Educação. Seu pedido não foi aceito, saindo do ministério apenas em março de 1945. (CANÇADO, 1991, p. 153-154)

6 Há um ofício do diretor do DIP, Major Antônio José Coelho dos Reis, de 11 de setembro de 1943, ao inspetor da alfândega comunicando a suspensão de "favores" à revista Diretrizes, que teria que quitar o pagamento de impostos das importações realizadas naquele ano.

7 A grande maioria desse material concerne à correspondência de populares enviada a Getúlio Vargas que se refere à educação. Vários são os despachos assinados por Drummond. 
Os arquitetos Oscar Niemeyer e Le Corbusier foram contratados para projetar a nova sede do Ministério da Educação. Em outubro de 1944, Niemeyer foi nomeado pelo prefeito do Rio para participar da comissão que projetaria a avenida Rio Branco. (CORREIO DA MANHÃ, 7 de outubro de 1944).

Em 1938, Mário de Andrade saia do Departamento do Patrimônio Histórico de São Paulo e assumia a direção do Departamento de Teatros e participava do Instituto Nacional do Livro. No Serviço do Patrimônio Histórico e Artístico Nacional, circulavam Manuel Bandeira, Portinari, Afonso Arinos de Melo Franco, Eneida de Morais, Oswald de Andrade, Villa-Lobos, Sérgio Buarque de Holanda, Antonio Candido - uns, declarados simpatizantes comunistas, outros declarados governistas e outros nem um nem outro. Em 1944, Sérgio Milliet tornou-se diretor da Biblioteca Municipal de São Paulo.

É preciso, ao falar destes escritores e intelectuais, pressupor suas dimensões ética e estética. As relações entre uma e outra são fundamentais por tratar-se de um período, no qual mais do que o exercício de controle da cultura, o estado passava a dominar o próprio processo de criação, propondo uma dimensão estética da política (GOMES, 1998; GOULART, 1990; LENHARO, 1986).

Dessa forma, muitos escritores descontentes com Vargas tentavam abrir brechas no interior dos próprios mecanismos de controle e foi, através de uma dessas brechas que, na cidade da garoa, numa segunda-feira, teve início o I Congresso Brasileiro de Escritores, no Teatro Municipal de São Paulo.

Cerca de duas mil pessoas, entre escritores, leitores e "fãs", compareceram às galerias para assistir à Sessão Inaugural do Congresso, cujo ingresso era público e gratuito.

\section{Contra a politicagem literária: a ética e a dignidade do escritor}

Um dia depois dos jornais brasileiros terem anunciado a rendição das tropas alemãs na Polônia, em 1945, partiam do Rio de Janeiro no dia 21 de janeiro, da Central do Brasil, as delegações estaduais do Rio, Amazonas, Bahia, Pará, Maranhão, Ceará, Piauí, Pernambuco, Rio Grande do Norte, Alagoas, Paraíba, Sergipe e Espírito Santo, além das delegações estrangeiras e de representantes de entidades convidadas para o Congresso. No dia seguinte, desembarcaram em São Paulo, na Estação da Luz, em grande festa. Mais tarde, chegaram as delegações do sul e de Minas Gerais.

Entre o assédio dos fãs, as delegações de escritores foram sendo recebidas na entrada do Teatro Municipal de São Paulo a partir das 15 horas. Naquela segunda-feira, 22 de janeiro, a 
rua que separava o teatro da filial brasileira da loja de departamentos britânica Mappin \& Webb, estava abarrotada de centenas de pessoas.

Passado algum tempo das 16 horas, Aníbal Machado subiu ao palco e tomou a direção dos trabalhos. Chamou, então, para compor a mesa diretora do Congresso Cristiano Cordeiro, Murilo Rubião, Otto Lara Resende, Roque Javier Laurenza, Dionélio Machado, Francisco de Assis Barbosa, Carlos da Silveira, Haddock Lobo, Jorge Amado, Mário Neme, Ernesto Feder e Sérgio Milliet. Este, na qualidade de presidente da entidade em São Paulo, declarou aberto o I Congresso Brasileiro de Escritores e apresentou o primeiro dos vários discursos.

Preocupado com atitudes de escritores alheios à sua própria condição e à situação da cultura no país, escritores afeitos à politicagem e não às questões literárias, Milliet tenta afinar com a assistência os objetivos do Congresso:

[...] Mas somos apenas escritores, e escritores desunidos, donos, por enquanto, de bem pequena parcela dessa consciência, e dessa solidariedade de classe que fazem a força dos agrupamentos profissionais e lhes outorgam a influência a que podem ter direito. [...] Eis-vos aqui em vossa terra, meus amigos, num momento grave de nossa vida, a fim de debatermos juntos questões de importância para a nossa classe. Questões éticas em primeiro lugar... éticas ainda em segundo, terceiro, e último lugares. Porquê, afinal, tudo não passa de ética. Não há vida coletiva sem código moral. [...] Se pudermos fixar em suas linhas gerais essa ética dos escritores, teremos alcançado o objetivo do Congresso. (MILLIET, 1945, p. 24).

O tom de unidade política é expressão das polêmicas criadas, ainda, durante a preparação do Congresso e se referia às questões que ali seriam discutidas. O clima era de festa e choveram aplausos ao escritor que passou a palavra a Aníbal Machado. Em seu discurso, Machado seguiu os mesmos caminhos de Milliet, apelando ao bom-senso de todos: - Só a comunhão nos importa.

Aplaudido, Machado continuou e diferenciou o literato do escritor. O primeiro, afirmou, produz literatura desinteressada, diletante, recreativa e torna-se termo pejorativo. $\mathrm{O}$ segundo, o escritor, é aquele "porta voz da sociedade, [...] com seus desejos, as suas cicatrizes e a respiração abafada do povo" (I CONGRESSO BRASILEIRO DE ESCRITORES, 1945, p. 25). Machado chamou a atenção dos escritores para sua própria situação: "Emancipar economicamente o trabalhador intelectual se impõe assim como o primeiro passo antes de pô-lo em condições de dignificar a sua obra e sua vida." (I CONGRESSO BRASILEIRO DE ESCRITORES, 1945, p. 26). 
O problema da dignidade do escritor está, neste caso, diretamente ligado à regulamentação dos direitos autorais. Tema, aliás, central desde a fundação da entidade em 1942, sem, no entanto, conseguir grandes resultados legais ou práticos. Mas este é um assunto programado para outro dia do congresso. Voltemos à dignidade do escritor.

Os debates do congresso tiveram início muito antes de Sérgio Milliet proferir seu discurso de abertura. Desde outubro de 1944, os pontos de encontro de escritores, principalmente no Rio e em São Paulo, fervilhavam conversas, reuniões e debates. As divergências não apareciam nas teses de direitos autorais ou nas de cultura, que deveriam ser entregues à Com. Org. do Congresso até 15 de dezembro de 1944, até questões internacionais eram quase consensuais. Os complicadores começam quando discutia-se a posição dos escritores frente à política de Vargas. Aí os argumentos explodiam e davam espaço para acusações.

Em carta a Hélio Pellegrino, poucos dias antes do início do Congresso, Mário de Andrade, por exemplo, deixava transparecer a sua insatisfação:

\begin{abstract}
Já sabemos de fonte certa que o filho da puta de um grande romancista pseudo-esquerdista vem atrapalhar a dignidade da inteligência brasileira propondo apoio ao governo. $O$ caso está se tornando grave porque o homem, além de ficar na posição comodista, arrasta muita gente para o mesmo comodismo fácil e gordo. Seria uma vergonha que, segundo penso, nos afeta a todos. Em São Paulo, há um grupo consciente e coeso que repudiará isso e as palavras-de-ordem de Moscou, da mesmo forma que repudia Churchill na Grécia e as Nações Unidas [...] na Itália.(CANÇADO, 1991, p. 205).
\end{abstract}

A carta anuncia as possíveis divergências no Congresso. Mário de Andrade, ainda que tenha participado anteriormente do governo de Vargas, não mediu palavras contra a posição que era ventilada de apoio ao governo, defendida pelos comunistas.

A controvérsia é mais complicada do que Mário de Andrade apresenta. Mas, antes, voltemos à dignidade do escritor antes que ela acabe em pancadaria.

Depois do pronunciamento de Aníbal Machado, o plenário ouviu emocionado a mensagem enviada pelo físico Albert Einstein aos congressistas. Seguiu-se, por algum tempo, a leitura de mensagens de congratulações e saudações ao Congresso. Todas recebidas com calorosos aplausos, ainda que parte da platéia estivesse perambulando pelas dependências do Municipal em busca de seu escritor predileto. A dignidade do escritor, como se fosse um jogral pré-ensaiado, aparece na mensagem de vários escritores. 
O poeta e jornalista pernambucano, Álvaro Lins aposta nos resultados do Congresso: "[...] Dessa reunião com certeza sairá mais valorizada dignidade nosso trabalho intelectual e consciência nosso papel escritores." (I CONGRESSO BRASILEIRO DE ESCRITORES, 1945, p. 17).

O tema da dignidade também aparece relacionado ao papel que pretendem estabelecer como grupo de profissionais. Ou relaciona-se com a "função social" que imaginam para si mesmos, como em Aníbal Machado:

É porém com orgulho senhores congressistas poder responder ao povo interessado no resultado de nossas discussões e perante os intelectuais aqui presentes de outros países que os escritores e artistas do Brasil estão capacitados de sua missão histórica; que consideramos o divórcio entre nós e o povo como a morte não do povo mas a nossa morte. (I CONGRESSO BRASILEIRO DE ESCRITORES, 1945, p. 26).

A tônica, assim como se apresenta no Congresso, parece ter sido preparada desde o início de sua organização. Foram unânimes as mensagens em defesa da dignidade do escritor, desde Alceu Amoroso Lima, católico convicto e membro da Academia Brasileira de Letras desde 1935, passando por João Mangabeira, a Afonso Arinos de Melo Franco. Não é necessário, no entanto, ser um leitor muito atento para entender que havia uma certa linguagem cifrada. A imprensa e as bocas ainda eram censuradas, e poucos foram os que ousaram pronunciar-se contra o nazifascismo, pela democracia e pela liberdade de expressão.

Por mais irônico que possa parecer, foi de dentro do Governo mas não em seu nome, que Carlos Drummond de Andrade saudou os colegas de profissão:

Não poderei estar presente congresso mas como delegado ABDE Rio e como trabalhador intelectual envio minha fraterna solidariedade aos esforços e iniciativas dos escritores ora reunidos para exame problemas profissionais e afirmação da consciência literária na luta mundial pela reconquista dos direitos perdidos e pelo acesso a novas liberdades. (I CONGRESSO BRASILEIRO DE ESCRITORES, 1945, p. 26)

Muito provavelmente Drummond escreveu seu telegrama do prédio recém inaugurado do Ministério da Educação, o Palácio da Cultura projetado pelo arquiteto Lúcio Costa, onde ainda trabalhava. Mas já neste período, conta o declarado comunista Aydano do Couto Ferraz, que andava em conversações com o poeta mineiro sobre a possibilidade de seu ingresso no PCB, o poeta estava "interessado" e começou a escrever artigos com opiniões 
políticas e chegou até a encomendar uma edição francesa de $O$ Capital, cuja leitura lhe foi um sonífero (CANÇADO, 1991, p. 181-183).

Após a leitura destas mensagens, o professor francês Roger Bastide fez um pronunciamento. Seu discurso, proferido em francês, avaliou a guerra, a ocupação alemã na França, a Resistência francesa, o fim inevitável do nazifascismo e afirmou que só a união entre os escritores, desde os católicos aos comunistas, poderia dar fim ao tempo do obscurantismo por qual passava a humanidade nas últimas décadas. (I CONGRESSO BRASILEIRO DE ESCRITORES, 1945, p. 31)

Bastide vinha de uma experiência que, a rigor, estava distante da experiência dos escritores brasileiros. Entretanto, em muito os escritores brasileiros se espelhavam na França e em seu movimento de "intelectuais" contra o fascismo. Vários escritores franceses, entre eles alguns dos que organizaram um movimento contra a guerra de 1914, patrocinaram o Congresso Antifascista de Amsterdã em 1932. Os escritores Romain Rolland e Henri Barbusse estavam à frente da iniciativa, cujo objetivo era mobilizar escritores e artistas contra a guerra e contra um possível ataque japonês à URSS. Participaram do Congresso cerca de 2.200 delegados, dentre os quais se destacam Albert Einstein, o escritor alemão Heinrich Mann (irmão de Thomas Mann), os escritores norte-americanos John Dos Passos (que também enviou uma mensagem de saudação ao congresso brasileiro) e Michael Gold, e o escritor francês André Gide. (LOTTMAN, 1987, p. 85-87).

Na primeira metade de 1933, houve outro congresso internacional, agora em Paris, do qual resultou a organização do Comitê de Luta Contra a Guerra e o Fascismo. O Congresso, intitulado Antifascista Europeu, foi realizado na Salle Pleyel, uma sala de concertos localizada na Rive Droite e contou com 3000 participantes. Os dois congressos ficariam conhecidos, posteriormente, como Movimento Amsterdã-Pleyel.

Daí em diante, várias foram as iniciativas dos escritores ligados ao antifascismo: formaram-se vários comitês, principalmente, na Europa; em junho de 1935, organizaram o Congresso Internacional de Escritores pela Defesa da Cultura na cidade de Paris (que inclui nomes como Aldous Huxley, Maximo Gorki, Louis Aragon, Tristan Tzara e André Breton), do qual resultou ações diversificadas como a criação da Associação Internacional dos Escritores pela Defesa da Cultura.

Com a Guerra Civil Espanhola, a Associação de Escritores chegou a organizar um congresso que percorreu vários países da Europa, entre eles, a Espanha, com esperanças de que tal evento ajudasse os republicanos. Com a queda de Paris, os escritores e artistas que não foram mortos, nem exilados, prepararam o movimento de Resistência. Era essa, em parte, a experiência levada ao congresso brasileiro materializada na presença e nas palavras de Roger Bastide - que foi aplaudido de pé. 
Depois de Bastide, foi dada a palavra ao adido cultural norte-americano no Brasil, William Rex Crawford. Principalmente a partir de 1942, várias organizações culturais brasileiras iniciaram trabalhos de intercâmbio cultural com os EUA. Havia uma intenção política de pela via cultural aproximar o Brasil dos americanos e, nesse sentido, já havia a proliferação de programas culturais norte-americanos no país, fosse no rádio ou no cinema, o que despertava o interesse de ambos os lados. Além disso, não parece coincidência que esse processo político e cultural fosse paralelo aos crescentes investimentos econômicos norteamericanos no país.

Para encerrar com chave de ouro os trabalhos da sessão inaugural, foi lida a mensagem dos correspondentes brasileiros junto às tropas da FEB, assinada, entre outros, pelo escritor Rubem Braga, a qual transcrevo na íntegra como síntese de um sentimento aparentemente comum instalado no Congresso:

Aos companheiros do I Cong. Bras. de Escritores - Somos testemunhas do valor com que os homens do povo do Brasil - e entre eles milhares de filhos dessa terra de S. Paulo - estão lutando nas montanhas cobertas de neve da Itália. Sabemos que todos os escritores dignos do Brasil são também - cada um em seu setor, com suas armas próprias - lutadores anti-fascistas. Que o escritor brasileiro se inspire no pracinha. Que se mire na sua coragem; no ânimo duro com que aceita um revés; na paciência com que espera; na presteza com que ajuda um companheiro; na decisão com que ataca; na obstinação com que resiste. Homens como esses pracinhas são filhos de um povo que bem merece uma vida digna. Não há vida realmente digna onde não há liberdade e justiça social. Temos a certeza de que o escritor brasileiro conhece e aceita a sua responsabilidade na conquista e na defesa das condições que permitem isso. Saudamos o congresso fazendo votos para que ele seja útil na defesa dos direitos dos escritores e, mais ainda, na defesa dos direitos comuns a todos os homens. - Itália, janeiro de 1945 - Egídio Squeff, Joel Silveira, Raul de Castro Brandão, Rubem Braga. (LOTTMAN, 1987, p. 1516).

Com o encerramento da sessão inaugural, muitos escritores foram para os locais onde estavam hospedados. Jorge Amado, que alugava um apartamento na avenida São João, a alguns quarteirões do Teatro e da Biblioteca municipais, recebeu vários amigos participantes do congresso. Outros foram para o coffee break nos bares próximos ao Municipal, alguns arriscaram o restaurante do Mappin. Mas a maioria ficou nas redondezas, pois ainda haveria atividade relativa ao congresso naquele dia no auditório da Biblioteca Municipal, na rua Xavier de Toledo, a dois quarteirões do Teatro Municipal.

A primeira sessão plenária do Congresso ocorreu ainda naquele dia, às 21 horas. Sérgio Milliet dirigiu-se à mesa e deu início aos trabalhos. Foi, então, formada uma comissão de trabalho, a qual se encarregou de realizar o credenciamento dos delegados, distribuir suas 
respectivas credenciais e nomear, em plenária, as cinco comissões de teses do congresso. $\mathrm{O}$ debate e a disputa política começavam efetivamente na divisão temática das comissões assim como na composição de cada uma delas.

Todas as comissões foram formadas através de indicação das delegações estaduais, sendo inicialmente pensadas para conter treze membros, passaram a ser constituídas por quinze delegados. A comissão de direitos autorais ("A"), presidida pelo conhecido jurista e poeta Paulo Mendes de Almeida; o jornalista baiano Homero Pires presidiu a comissão ("B") de cultura e assuntos gerais; a comissão de assuntos de teatro, rádio, imprensa e cinema foi presidida pelo humorista Aparício Torelly, conhecido desde a década de 1930 como Barão de Itararé e como declarado comunista.

$\mathrm{Na}$ comissão de assuntos políticos encontramos praticamente todos os nomes diretamente envolvidos na própria organização do congresso: Alberto Passos Guimarães, Jorge Amado, Astrojildo Pereira, Osório Borba, Eduardo do Prado Kelly, Jair Rebelo Horta, Carlos Drummond de Andrade (que não compareceu ao evento), Moacir Werneck de Castro, Carlos Lacerda, Caio Prado Júnior, Paulo Emílio Sales Gomes, Dionélio Machado, Arnon de Melo, Fritz Teixeira de Sales e Raul Riff.

E, por fim, foi nomeada a comissão de redação e coordenação, encarregada entre outras tarefas de dar a redação final às teses aprovadas em plenário e coordenar todos os trabalhos das respectivas comissões.

Depois da plenária, naquela noite, Jorge Amado e alguns escritores comunistas, como a escritora Alina Paim (membro da comissão de direitos autorais), Dionélio Machado (da mesa diretora do congresso e da comissão de assuntos político), Dalcídio Jurandir (da comissão de cultura e assuntos gerais), Oswald de Andrade, Aparício Torelly e Vinícius de Morais (os três da comissão de teatro, imprensa, rádio e cinema), e Moacir Werneck de Castro e Raul Riff (ambos também da comissão de assuntos políticos com Jorge Amado). A posição de "união nacional" deveria ser defendida pelos comunistas no congresso e Carlos Lacerda, o mais decidido contra a posição comunista, deveria ser alvo de argumentos para que mudasse de opinião.

No dia seguinte, às 14 horas foram iniciadas as primeiras reuniões das comissões, no Centro do Professorado Paulista. A tarde foi cansativa. As tantas teses foram primeiramente separadas não pela comissão de redação e coordenação, mas sim pela mesa diretora do congresso "pela natureza do assunto", (I CONGRESSO BRASILEIRO DE ESCRITORES, 1945, cap. II, art. 30) e distribuídas pelas comissões que lhes cabiam tematicamente. Enquanto isso, nas comissões temáticas ocorriam as eleições para presidentes, secretários e relatores - cada membro das comissões tinha uma tarefa muito específica, mas ficava garantido aos autores das teses que mais de um membro leria cada tese. 
Chegando as teses nas respectivas comissões, foram distribuídas entre os relatores. Os trabalhos das comissões foram encerrados, já que os relatores deveriam ler as teses para, no dia seguinte pela manhã, apresentarem os primeiros relatórios, que ainda deveriam ser aprovados pelo conjunto da comissão. Só assim, de acordo com o regimento, poderiam as teses chegarem a ser debatidas em plenário.

Mas isso tudo estava acontecendo com 70, no máximo 75 pessoas de um congresso com mais de 250 escritores. E como o dia havia sido livre para o restante dos delegados, por volta das oito horas da noite - horário em que se encerraram as atividades das comissões -, compareceram ao Teatro Colombo para assistirem à peça Hoffman de Alfredo Mesquita, cuja renda seria revertida em benefício do congresso. A encenação ficaria por conta do Grupo Experimental de Teatro, fundado e dirigido pelo autor da peça ${ }^{8}$. (ESTADO DE SÃO PAULO, 19 de janeiro de 1945) Alfredo Mesquita, paulistano nascido em 1907, cursou a Faculdade de Direito e a de Ciências e Letras durante a década de 1930. Foi também neste período, em 1936, que estreou no Teatro Muncipal de São Paulo com a peça Noite de São Paulo. No ano seguinte ganhou o prêmio do Departamento Municipal de Cultura, na categoria drama.

Mas, muito provavelmente, a mesa diretora e os membros das comissões não estavam lá para prestigiar o escritor Alfredo Mesquita e o seu Grupo Experimental de Teatro. Estes deveriam estar em alguma das festas, nas quais "a intelectualidade e a sociedade paulistanas homenageavam os ilustres participantes desse I Congresso, convidando-os às suas casas, oferecendo-lhes lautos jantares e animados coquetéis". Ao menos é isso que Zélia Gattai nos faz acreditar. (GATTAI, 1982, p. 29) Jorge Amado, aquele que daí a alguns meses se tornaria marido de Zélia, no entanto, arrisca uma lembrança mais picante:

Fora das plenárias e das comissões era a festa e que festa! Ininterrupta, delirante, as rédeas soltas. Coquetéis [...], festinhas, danças improvisadas, bate-coxas animados, comilanças, beberanças e, acima de tudo, a boa fodilhança: como se fodeu nesse Congresso, inimaginável! Vinicius de Morais, galã de cinema, ia de mão em mão, melhor dito de xoxota em xoxota. Tampouco posso me queixar. (AMADO, 1992, p. 20).

Entre a lembrança de uma orgia narcísica de Jorge Amado e a recatada de Zélia Gattai, que de resto podemos imaginar não ter sido nem uma coisa nem outra nos extremos, as festas foram fatos anunciados publicamente pelos jornais.

8 No Dicionário Literário Brasileiro de Raimundo de Menezes. Rio de Janeiro: LTC, 1969. p. 443, essa peça não consta de sua bibliografia. 
No dia seguinte, quarta-feira às oito da manhã, enquanto os membros das comissões e os da mesa preparavam seus pareceres para a reunião nas comissões ou recuperavam-se de uma possível ressaca, dois ônibus lotados de escritores partiam da livraria Brasiliense, na rua Dom José de Barros, em direção ao norte da cidade. Os delegados visitaram o Horto Florestal, único do tipo na América Latina naquele período, recobria quase toda a Serra da Cantareira; hoje, o Horto se reduz a uma pequena área no início da descida da Serra. ${ }^{9}$ (ESTADO DE SÃO PAULO, 25 de janeiro de 1945)

Às 14 horas, teve início a segunda plenária do Congresso no Centro do professorado Paulista-CPP. Na primeira parte, já tendo iniciado a apresentação dos primeiros relatórios de trabalho das comissões temáticas, percebeu-se que as comissões pouco puderam produzir sem terem nenhum relatório conclusivo possível de ser apresentado ao plenário. Das duas uma: ou a festa da noite anterior foi muito divertida ou a quantidade de trabalho foi maior do que se esperava. Eu fico com as duas.

No entanto, o dia não passou em brancas nuvens. Lá pelas tantas, depois de várias desculpas dos relatores das comissões, Wilson Martins, que contava com 24 anos e acabara de se tornar bacharel pela Faculdade de Direito do Paraná pediu a palavra e solicitou que a mesa providenciasse cópias dos relatórios globais ao conjunto dos delegados. Em seguida, Clóvis Ramalhete, da comissão de direitos autorais, declarou não participar do parecer da comissão, pois achava que todos os assuntos apresentados na comissão deveriam ir para as plenárias. O debate começou a esquentar, já que vários congressistas concordavam com Ramalhete.

A cantilena tinha seus motivos. O Regimento Interno do Congresso estabelecia que a tese que tivesse o parecer negativo referendado pela comissão, não seria sequer mencionada nas plenárias. Alguns delegados, no entanto, pronunciaram-se contrários ao controle do que seria debatido em conjunto. Carlos Lacerda concordou, mas pediu uma interpretação do Regimento Interno mais "liberal" por parte da mesa. O ensaísta Fernando de Azevedo, fundador e diretor da Cia. Editora Nacional, pediu que regimento fosse respeitado e que as comissões fossem soberanas. Do fundo do auditório, ouviu-se um princípio de vaia.

Sérgio Milliet tentou apaziguar os ânimos avisando da impossibilidade de ter cópia dos relatórios globais a todos os congressistas, porque não havia estrutura nem dinheiro. Joracy Camargo, membro da Sociedade Brasileira de Autores Teatrais e, no congresso, da comissão de Teatro, imprensa, rádio e cinema, tentou ler a proposta de Fernando de Azevedo. Quando acabou seu tempo, a mesa pediu que ele encerrasse. Continuou e ouviu sonoros "cala boca!" da platéia, principiando um tumulto que o fez calar.

9 Os delegados foram recebidos pelo diretor do Serviço Florestal do Estado, Arnaldo Araújo Jordão. 
O jornalista comunista Pedro Motta Lima politizou a discussão: "Não podemos dar ao País um espetáculo que não corresponda aos sentimentos democráticos do nosso povo. Então, nós não podemos admitir que haja outro poder soberano que não o do Plenário do nosso Congresso." (I CONGRESSO BRASILEIRO DE ESCRITORES, 1945, p. 47)

Seguiram-se, então, várias intervenções em defesa da soberania das plenárias do congresso. Quando já se encerrava a discussão, o humorista e comunista Aparício Torelly pediu a palavra:

O Congresso é soberano e a comissão não o é. Isso seria delegar à minoria (da qual faço parte) um poder soberano, em desacordo com os princípios democráticos. De maneira que, como presidente de uma dessas comissões, abdico desde já desta autoridade soberana, para transferi-la ao Congresso, porquê a ele me pertence. (I CONGRESSO BRASILEIRO DE ESCRITORES, 1945, p. 49)

Para organizar os debates, Aníbal Machado suspendeu a plenária para que as propostas de mudança do regimento pudessem ser elaboradas para entrarem em processo de votação.

Carlos Lacerda, Fernando de Azevedo e Martins de Almeida elaboraram uma proposta: "Proponho que todas as conclusões das comissões sejam submetidas a discussão e aprovação em plenário." (I CONGRESSO BRASILEIRO DE ESCRITORES, 1945, p. 50) Mais três propostas foram apresentadas, todas propondo modificar o regimento nos mesmos termos da proposta de Lacerda. Uma destas propostas foi apresentada pelo escritor comunista Milton Pedrosa, a revelia de Jorge Amado, que havia feito um acordo com Carlos Lacerda em nome dos comunistas do congresso para apoiar sua proposta, a qual foi aprovada por unanimidade (nem Pedrosa votou em sua proposta?).

Depois da confusão, teve início a apresentação dos relatórios da comissão de cultura, que não demorou muito a ser encerrada, pois as comissões não estavam preparadas para apresentação de todos os pareceres já que o regimento acabava de ser mudado. A terceira sessão plenária foi convocada para às 20 horas no mesmo lugar.

À noite, antes de serem apresentados os trabalhos da comissão de cultura, foi aprovada a proposta do escritor português Jayme Cortesão, a qual formava uma comissão com Antônio Amorim, Jayme de Moraes, Artur Ramos, Sérgio Buarque de Holanda e José Honório Rodrigues, que se encarregaria de organizar a Sociedade Luso-Afro-Brasileira, cujos objetivos seriam o de estudar e defender o "patrimônio cultural" comum destas tradições. Não se tem notícia se a Sociedade foi ou não formada e a quantidade de comissões formadas durante o congresso bateu a casa das dezenas. 
A comissão de cultura, então, passou a coordenar o restante dos trabalhos noturnos. Sérgio Buarque de Holanda apresentou o parecer negativo da tese de Ernesto Heli da Selva, concluindo que de acordo com o art. $19^{\circ}$ do regimento "o Congresso não deve tomar conhecimento da tese". O argumento de Holanda, baseado no regimento, diz respeito ao trecho conclusivo da tese:

Sugerimos a este Congresso dirigir a S. Excia., o Sr. Presidente da República, primeiro anti-fascista da República Democrática do Brasil, a afirmativa da nossa solidariedade pela sua atividade que vem calando fundo em nossa mentalidade de anti-fascistas conseqüentes [...] (I CONGRESSO BRASILEIRO DE ESCRITORES, 1945, p. 61)

A proposta foi vaiada. Outras propostas como a formação de um sistema público e gratuito de ensino, ou as propostas de formação de bibliotecas nos bairros afastados dos centros urbanos, ou, ainda, as de bibliotecas ambulantes, tiveram suas conclusões práticas reduzidas ao encaminhamento às "autoridades competentes" - o que significava enviar as propostas aos governos federal, estadual ou municipal conforme o caráter de cada proposta ou, em última instância, o que talvez desse no mesmo, tornaram-se letra morta na ata do congresso. Foram ainda debatidas outras teses.

Na quinta-feira, aniversário da cidade de São Paulo, a programação do congresso ficou reservada para as comissões. Mas ainda houve tempo para uma atividade em conjunto: aproveitando a data de aniversário da cidade, foi inaugurada a Seção de Arte da Biblioteca Municipal e Sérgio Milliet, como diretor da biblioteca, proferiu um discurso, seguido pelo presidente da ABDE, Aníbal Machado, que versou sobre as artes plásticas no Brasil. Porém, antes da inauguração, que aconteceu por volta das 13 horas, alguns delegados participaram do coquetel oferecido aos congressistas na União Cultural Brasil-Estados Unidos. Esta atividade não foi para todos os delegados e o público em geral, como também não foi o jantar oferecido pelo casal Lasar Segall.

\section{Com medo do quê?}

A quarta sessão plenária teve início na sexta-feira às 14 horas, no Centro do Professorado Paulista, com a leitura da mensagem do embaixador dos EUA no Brasil aos escritores. Depois de alguns informes e acertos, foram apresentados os relatórios finais da comissão de cultura.

A primeira tese apresentada foi a de Humberto Bastos, que solicitava apoio do congresso na exigência junto ao governo para a formação do Instituto Nacional de Educação a fim de coordenar uma campanha nacional de alfabetização. Após sua rejeição, foi 
apresentado o parecer sobre a tese de Dalcídio Jurandir e Astrojildo Pereira sobre o mesmo assunto.

O parecer do carioca José Honório Rodrigues foi taxativo: "Trata-se de valiosa contribuição, estudando os meios práticos de combate ao analfabetismo". O paulistano Paulo Mendes de Almeida, chefe da Procuradoria Geral do Estado, pronunciou-se contrário alegando impedimento regimental. No mesmo sentido, falou Marinho Rego. Por outro lado, em defesa de Pereira e Jurandir, retomou a palavra Honório Rodrigues e pronunciou-se ainda Alberto Guimarães. Este último, baiano que era, lembrou aos congressistas que a proposta havia sido inspirada na experiência dos jovens universitários baianos que iniciavam uma campanha de alfabetização "popular" em conjunto com a Secretaria Municipal de Educação.

A tese foi colocada em votação e o tumulto foi grande, tendo a mesa diretora que fazer a votação novamente. Porém, no fim, foi aprovada. Mas Marinho Rego, tendo perdido a votação, pediu que se incluísse um adendo à proposta de Dalcídio Jurandir e Astrojildo Pereira. De pronto, Caio Prado Júnior se pronunciou contrário, afirmando que tal adendo contrariava as propostas da tese. E quando seguiu-se a votação, Marinho Rego perdeu novamente.

Sérgio Buarque de Holanda leu o parecer da tese "O estudante pobre em face da cultura" de José Lazarini e Irineu Stronger. Tal tese propunha a inclusão de um certo número de vagas gratuitas nas escolas secundárias e universitárias, que seriam distribuídas aos estudantes "pobres". O parecer de Holanda foi negativo, pois a tese seria "demasiada ingênua, para não dizer inocente.” (I CONGRESSO BRASILEIRO DE ESCRITORES, 1945, p. 88). Mas teve que voltar atrás, pois o restante da comissão discordou de seu parecer, propondo que a tese fosse publicada nos anais. O socialista Paulo Emílio Sales Gomes saiu em defesa da tese e obteve o apoio necessário para que ela fosse aprovada.

Buarque de Holanda leu, em seguida, o parecer elaborado por Lívio Xavier sobre a tese "Estudos regionais", cuja autoria pertence ao folclorista baiano e comunista Édison Carneiro. O parecer de Lívio Xavier foi elogioso e recomendou a aprovação da tese:

[...] por tratar-se de assunto de interesse geral qual seja a publicação mais sistemática e divulgação mais ampla das monografias de caráter regional que estudem do ponto de vista da sua formação particularista a história e a economia do Brasil. (I CONGRESSO BRASILEIRO DE ESCRITORES, 1945, p. 90) 
Desta forma ela foi aprovada por unanimidade e, em seguida, Fernando de Azevedo leu um documento sobre a democratização da cultura, assinado por ele próprio, e mais Cruz Costa, Carlos Lacerda, Antonio Candido, Pedro Mota Lima, entre outros socialistas e democratas, além de Astrojildo Pereira. O documento foi o coroamento de uma perspectiva comum em torno das propostas de cultura e indicava, tal como um manifesto, os caminhos a serem seguidos pelos escritores:

Considerando que à cultura incumbe o dever de se entregar inteiramente ao estudo, debate e solução dos grandes problemas do país e à defesa e amparo das classes que até hoje viveram privadas de seus benefícios; [...] Considerando que o problema da democratização da cultura está intimamente ligado ao da criação de uma ordem social, mais justa e mais humana em que haja igualdade de oportunidade para todos; [...] Sugere à ABDE, como instituição de classe, e a todos escritores que a constituem que [...] 1. cooperem na defesa do conceito de liberdade [...]; 2. defendam os direitos e a dignidade da pessoa humana [...]; 3 . reconheçam e defendam [...] uma vida social democrática de tal modo organizada que permita e favoreça as diferenças individuais [...]; 4. contribuam para a reestruturação do sistema nacional de educação [...]; 5. procurem promover e prestigiar a participação maior das massas na cultura [...]; 6. apoiem e estimulem as investigações regionais [...]; 7 . procurem dilatar a ação desses poderosos instrumentos de informação [cinema, jornal, revista, livro e, sobretudo o rádio], de influência educativa e artística e de irradiação da cultura; 8. tenham presente que a literatura e a arte desempenham um papel social [que] podem realizar uma fecunda comunhão entre o povo e os criadores da cultura; 9. que considerem, pois, os escritores a função que lhes cabe ou que podem exercer no processo de democratização da cultura, o qual não se realiza somente, como se supõe, de fora para dentro, sob pressão de causas externas (reformas e medidas de caráter econômico, social, político, escolar, etc.), mas pela força interna da criação e de renovação, de uma cultura de mandato social, enraizada na vida do povo, e alimentada nas suas tradições e lembranças, nas suas necessidades e nos seus problemas, nos seus sofrimentos e nas suas aspirações; 10. que apoiem e estimulem toda a literatura inspirada em nossa melhor tradição liberal [...](I CONGRESSO BRASILEIRO DE ESCRITORES, 1945, p. 95)

O documento parece ter sido o mais bem elaborado daqueles que foram apresentados pela comissão de cultura e, ainda assim, não foi votado; foi apenas encaminhado, como sugestão, para a comissão de coordenação e redação.

Ao mesmo tempo em que o documento expressou uma certa unidade de opiniões gerais sobre o papel "social" do escritor, ele revelou conflitos de outra natureza.

Astrojildo Pereira foi um dos fundadores do PCB em 1922, integrando-se em sua direção nacional. Em fins dos anos trinta, Astrojildo fora afastado do partido, por uma lado, porque 
defendia a formação de uma frente com o grupo de Luís Carlos Prestes - avaliação contrária à das direções superiores da organização comunista, que avaliavam Prestes como um "líder pequeno-burguês" -, por outro e como sua conseqüência, a política partidária sob sua direção havia se tornado "pequeno-burguesa". Esse foi o processo de "proletarização". Desde então, Astrojildo ficou afastado do partido, aproximando-se vez por outra. No congresso, Astrojildo expressava o seu repúdio à CNOP, circulando e juntando-se aos socialistas e democratas, não aceitando as ordens de Jorge Amado. Astrojildo Pereira deveria ficar olhando aquele "moleque" e bem poderia pensar: "Quem é esse menino que quer me dar ordens? Eu fundei o partido comunista e ele nem saiu das fraldas." Ou pior: "Quem é esse moleque de recados de um grupelho que se diz a direção comunista?" Mas nisto ele estava com todos os comunistas: faltava que Prestes reconhecesse ou não o grupo. E ele, assim que saiu da prisão, alguns meses depois do congresso, acabou por reconhecê-lo e por assumir o cargo de secretáriogeral da organização.

Carlos Lacerda também tinha feito parte do PCB e, só para lembrar, fazia parte daquele grupo chamado em 1938 de "os cinco mosqueteiros com idéias comunistas". Mas, no ano seguinte Lacerda escreveu um artigo sobre o PCB em $O$ Observador Econômico e Financeiro, que não agradou a direção do partido. Lacerda se afastou, então, dos outros mosqueteiros e viu o seu nome associado ao trotskismo, a provocador, agente da GESTAPO, etc.

Agora, no congresso, liderava com outros escritores uma bancada que se denominava "democrática", constituída por socialistas e democratas independentes que formariam futuramente algumas pequenas organizações como, por exemplo, a Esquerda Democrática, a União Democrática Socialista, o Partido Socialista Brasileiro e, em outros casos, como o de Lacerda, a União Democrática Nacional - formada no mês seguinte da realização do congresso. Carlos Lacerda foi um dos líderes e mentores da UDN, apresentada como uma grande frente anti-Vargas. Como os comunistas defendiam a "união nacional", que incluía a defesa das eleições para uma constituinte com Getúlio Vargas na Presidência da República. Carlos Lacerda, anti-varguista que era, não poderia concordar com a posição dos comunistas.

Antonio Candido e Sérgio Buarque de Holanda nunca estiveram perto do PCB, mas acabariam juntos fundando o PSB no ano seguinte.

Mas deixemos de querer antecipar as coisas, porque houve ainda um outro conflito e este, talvez, não seja assim tão transparente como os conflitos partidários. $\mathrm{E}$ como tal ele começa a se esboçar com a apresentação dos relatórios da comissão de teatro, rádio, cinema e imprensa.

O primeiro relatório apresentado, da subcomissão de imprensa, por Paulo Zinng, tinha apenas uma tese para apreciar e resolveu apresentar algumas "recomendações" ao congresso, que variou da absoluta condenação da censura organizada pelo DIP aos veículos de comunicação, ao estabelecimento de uma tabela de salários da ABDE. Plínio Melo, diretor 
do Sindicato dos Jornalistas Profissionais, disse que o congresso soube exprimir muito bem o pensamento dos jornalistas profissionais, aplaudindo de pé o relatório de Zinng.

Vinicius de Morais apresentou, então, o relatório da subcomissão de cinema. Não tendo nenhuma tese a ser apresentada, o relator elaborou algumas propostas a serem encaminhadas pela $\mathrm{ABDE}$. $O$ relatório começa afirmando a ligação de longa data entre a literatura e o cinema. Para terminar propondo, entre outras, a obrigatoriedade de críticos livres de cinema na grande imprensa e na de literatura, a criação de uma Filmoteca Pública, a obrigatoriedade de exibição de "bons filmes educativos", que haja tradução dos letreiros de filmes estrangeiros, que $\mathrm{ABDE}$ "recomende aos poderes competentes a criação de clubes de cinema no país [...]" (I CONGRESSO BRASILEIRO DE ESCRITORES, 1945, p. 100). Lembramos que Vinicius de Morais acabava de traduzir a biografia-exaltação de Stalin que Henri Barbusse publicara em 1935. A tradução, Stalin: um mundo visto através de um homem, seria publicada ainda em 1945.

A comissão de teatro apresentou apenas duas teses. Álvaro Moreyra leu o parecer positivo sobre a tese de Joracy Camargo, "O teatro do povo". Ainda que o parecer tenha sido pela aprovação da tese, a comissão não concordou com tudo que Camargo afirmou. A discordância dizia respeito a esta passagem da tese:

A preguiça mental do nosso povo, que decorre da sua própria formação apressada, pela influência do clima, longe de afastá-lo do teatro, ao contrário, obriga-o a procurar a única forma de expressão artística que lhe satisfaz a irresistível tendência para a materialidade, ou melhor, para fazer da idéia uma realidade viva e plástica. [...] Aí está a razão pela qual o nosso público, na falta dos antigos espetáculos de circo, com suas pantominas de poucas palavras e de ação intensa, se movimentou em massa, apaixonadamente, para os campos de futebol, o esporte que passou a constituir o verdadeiro teatro nacional. (I CONGRESSO BRASILEIRO DE ESCRITORES, 1945, p. 185).

O parecer de Moreira se parece com um antigo professor ensinando algo a um aluno principiante:

Não se deve falar no baixo nível mental do nosso povo. Deve-se falar no baixo nível mental do teatro que se dá ao nosso povo - com exceções que os intérpretes insistem em derrotar. $\mathrm{E}$ às exceções pertence Joracy Camargo. Aliás sua tese é um desabafo e um protesto. (I CONGRESSO BRASILEIRO DE ESCRITORES, 1945, p. 101). 
Aqui há uma função devastadora, que ilumina qual papel o escritor pleiteia como seu. A partir daqui e seguindo os argumentos da tese de Camargo encontramos talvez, um ponto de afinidade entre os dois, na definição de "teatro do povo": "[...] tratará sempre de temas coletivos, transplantando para o palco os conflitos da maioria, sem o esquematismo e o psicologismo a que estão obrigados os autores da pequena-burguesia." (I CONGRESSO BRASILEIRO DE ESCRITORES, 1945, p. 186).

Aparece, então, o tipo de teatro contra o qual se opõe o "teatro de massas". O teatro da pequena-burguesia que, segundo eles, acabava por encher as cabeças do "povo" de dramas existenciais, que não tinham nenhuma utilidade para suas vidas. O escritor, por ele mesmo, acaba sendo incorporado à essa concepção eugênica, tornando-se aquele que intervém na formação de um "povo" de "nível mental" elevado:

\begin{abstract}
Precisamos tornar os indivíduos da massa úteis a si mesmo e à coletividade habilitando-o a reivindicar coletivamente a satisfação de suas necessidades, pelo esclarecimento dos conflitos em que se debatem, para que os responsáveis diretos pelos seus destinos encontrem maior facilidade na solução dos problemas da maioria, e possam contar com a colaboração do povo na obra de sua própria salvação. (I CONGRESSO BRASILEIRO DE ESCRITORES, 1945, p. 190-191).
\end{abstract}

Quem são os tais "responsáveis diretos pelos seus [povo/massas] destinos"? A ideia missionária aparece, então, na forma de intervenção direta dos escritores, "como líderes naturais de todas as correntes populares", na administração pública. É muito provável que avaliassem que a administração pública de Getúlio Vargas não tenha sido o lugar mais propício para este tipo de intervenção; lugar que, em todo caso, foi para alguns. E, talvez por isso, ambos estivessem presentes no Instituto Nacional de Música no Rio de janeiro, alguns meses depois, recebendo das mãos de Prestes a carteirinha de filiado comunista.

Os congressistas aprovaram a tese de Camargo e, indo adiante, aprovaram a tese de Pompeu de Souza, cujo título é esclarecedor, "Pela criação de um teatro nacional". No mesmo sentido da tese que a precedeu, esta afirma que o teatro no Brasil "não presta porquê é escrito por incapazes". Concluindo que só quando "verdadeiros escritores" escreverem peças, poderá o teatro sair da "sub-cultura" em que se encontra, por tratar-se de interpretações baseadas em "sub-literatura". O teatro, então, segundo ele, para livrar-se deste mal deve livrar-se do interesse comercial que o dominou. Para isso, nada melhor do que, segundo ele, o teatro continuar a receber e exigir mais financiamentos do "poder público". Intervenção direta do escritor e patrocínio do poder público, eis a receita que comunistas e nãocomunistas encontravam em conjunto contra os males dos interesses comerciais no teatro brasileiro. 
Não foram muito diferentes as teses apresentadas pela subcomissão de rádio. Na tese " $O$ rádio e o escritor", seu autor Nilo Ruschel afirma a diferença entre o jornalismo falado e o escrito, cabendo ao primeiro fornecer as premissas para que o segundo fique com as análises. $\mathrm{O}$ mérito desta dessa tese está na explicitação do inimigo a quem se deve combater o escritor no rádio:

$\mathrm{O}$ rádio-teatro surgiu a bem pouco tempo. E os seus primeiros intérpretes foram recrutados no teatro? Mas em que espécie de teatro? No de segunda ordem, entre os elementos cansados, desses que iam vivendo ao sabor de efêmeras companhias, levando desta para outra a sua figura sempre-a-mesma, com aquele sotaque fortemente lusitano. Foram seduzidos pelo rádio e nele trabalham até hoje, burocraticamente impassíveis. O pior é que formaram escola. Impuseram estilo e mentalidade. Os que vieram após, tomaram-nos por modelo. E daí esse curso falsíssimo seguido pelo teatro radiofônico, que está pedindo um trabalho exaustivo de crítica. (I CONGRESSO BRASILEIRO DE ESCRITORES, 1945, p. 204).

Por fim, afirma que o rádio precisa se livrar do "oportunismo comercial" que tomou conta de sua programação e baixou a sua qualidade, o que pode a intervenção "firme" do escritor.

Seguindo os mesmos passos de argumentação, a tese de Milton Pedrosa foi apresentada ao plenário do congresso. Incluiu-se aí, no entanto um item que vale a pena comentar. Segundo o comunista, a falta de liberdade de atuação do escritor no rádio é devido a vários fatores, dentre os quais eu destaco:

c. o 'fan', cuja mentalidade, num país em que a porcentagem de analfabetos segue sendo assustadora, tem os limites de suas exigências, no que diz respeito à cultura, muito abaixo daquilo com que se consegue um programa literário de valor cultural. (I CONGRESSO BRASILEIRO DE ESCRITORES, 1945, p. 210).

Será mesmo que Milton Pedrosa achava o "Fan" um impecilho à "elevação" cultural do país? Será que os escritores achavam mesmo o teatro, o cinema e o rádio grandes ameaças à formação cultural do "povo"? Só poderíamos tentar responder se a pergunta for mais ampla.

A questão não era a suposta subcultura ou subliteratura que estes novos e poderosos veículos de comunicação vinculavam. Mas eram os novos espaços que estes veículos criavam ao atingirem uma quantidade maior de pessoas. Espaços, dos quais os escritores e seus livros saiam perdendo. A industrialização da cultura que acabou criando um público 
consumidor infinitamente maior do que o dos livros, tornou-se inimigo do escritor. Essa cultura de massas que foi sendo criada colocou o escritor numa posição em que dividia o seu prestígio público com o apresentador do Repórter Esso, com a estrela Ava Gardner, com a dupla humorística Jararaca e Ratinho, etc. O "fan" não queria somente o autógrafo de Monteiro Lobato, ele queria mais. Assim, para os escritores era preciso que se criasse uma legislação que os protegesse como categoria profissional.

\section{O pai dos pobres, a mais-valia e a literatura privada}

O I Congresso Brasileiro de Escritores acabava de entrar em sua fase de encerramento. A terceira parte da plenária do dia 26, tratou da questão dos direitos autorais. Desta discussão, participaram os escritores mais engajados na militância da ABDE e como as teses apresentadas são repetitivas, apenas elencarei os pontos discutidos e aprovados, que acabaram formando o documento "Os direitos autorais do escritores" (ante- projeto de lei).

O ponto central dos direitos autorais é o de direito à propriedade literária. Deste ponto emergiram várias propostas e uma delas defendia que se o autor morresse sem deixar herdeiros que a sua obra caisse imediatamente no domínio público, que significa o uso da obra sem pagamento de direitos autorais. No entanto, a ela foi adendada a proposta de que, ao cair em domínio público, a obra reverta o pagamento de uma porcentagem dos direitos autorais a uma Caixa Assistencial dos Escritores ou de um Fundo ligado diretamente à ABDE.

Outra tese propôs que a $\mathrm{ABDE}$ criasse tabelas de remunerações tanto para traduções, como para colaborações esporádicas em jornais e revistas. Foi incluída, também a proposta de criação de uma outra tabela pela ABDE que estabeleceria uso patamares mínimos de remuneração de escritores contratados. Duas outras teses apresentaram propostas à semelhança da recém-prumulgada Consolidação das Leis do Trabalho: uma que estabelecia a Carteira de Trabalho do Escritor e outra que atribuía ao Instituto Nacional do Livro, ligado ao Ministério da Educação, a tarefa de fiscalizar o cumprimento dos direitos autorais e aplicar multas se necessário.

Passados já algum tempo nessa discussão, a mesa diretora do congresso recebeu a indicação da tese de Arístides Lobo, intitulada "O conteúdo mistificador de domínio público". A tese que representava o grupo trotskista, mais tarde organizado em torno do jornal Vanguarda Socialista, lembrou aos congressistas um problema interessante:

Eis porquê se me afigura razoável pedir que o I Congresso Brasileiro de Escritores não se converta por uma compreensão inadequada do problema em órgão dos editores, isto é, exatamente dos que já possuem 
o privilégio de acumular a mais-valia resultante da exploração do trabalho literário e artístico. Enquanto vivemos sob o império do modo de produção capitalista, devemos reclamar a perpetuidade dos direitos autorais e a sua transferência, exclusivamente, aos herdeiros do autor, os quais serão os seus descendentes diretos ou, na falta destes, os escritores organizados em associação. (I CONGRESSO BRASILEIRO DE ESCRITORES, 1945, p. 117).

Arístides Lobo pode ter suas razões para denunciar que os interesses dos editores não é o mesmo que os dos escritores e, talvez, ele também tenha percebido que ambos interesses apareciam juntos nas propostas aprovadas feitas pela comissão de direitos autorais, já que muitos dos escritores presentes no congresso eram também editores e, obviamente, foi rejeitada, assim como foram todas as propostas enviadas pelos trotskistas. ${ }^{10}$

Por isso, a proposta de "domínio público" não foi pensada em termos de interesses antagônicos como imaginou Lobo. Ao contrário, Caio Prado Júnior (proprietário da Livraria e Editora Brasiliense), Nelson Palma Travassos (proprietário da Empresa Gráfica Revista dos Tribunais), entre outros, participaram ativamente das discussões, propondo questões referentes ao mesmo tempo ligadas à proteção legal dos escritores frente ao mercado editorial, e medidas que possibilitassem a criação de um parque industrial gráfico. Nesta luta, escritores e editores não mediram esforços em ter aliados importantes como os proprietários das indústrias de papel ${ }^{11}$.

Assim, nas discussões sobre direitos autorais encontram-se interesses econômicos de três ordens ligados diretamente à sobrevivência material do escritor. A primeira que estabeleceu a proteção salarial, a segunda que propôs investimentos no mercado editorial nacional e, por último, o direito de propriedade.

Em torno do I Congresso Brasileiro de Escritores criou-se uma memória cristalizada que atingiu tanto seus participantes que o rememoram, quanto a bibliografia acadêmica que tem investigado a ação dos intelectuais. (DULLES, 1985; GATTAI, 1982; HAUSSEN, 1997; MOTTA, 1994) Essa memória foi construída com base a ideia de que o congresso representou, por um

10 Além das já citadas, ver também a proposta apresentada por Patrícia Galvão e Geraldo Ferraz, Idem, p. 124.

11 É o que se nota quando se apresenta a lista de contribuições financeiras recebidas para a realização do congresso, que contava com, por exemplo, Indústria de Papel Simão Ltda. ( Cr \$ 5000,00), Indústrias de Papel Klabin - propriedade de Horácio Lafer $(5000,00)$, Cia. Editora Nacional $(5000,00)$, Livraria José Olympio Editora $(5000,00)$, Editora Globo (5000,00), Livraria Martins Editora $(5000,00)$, etc. OESP, 21 /janeiro/1945. Como referência de preço indico que o preço do jornal Correio da Manhã custava ao leitor nos dias de semana, 0,40 e nos domingo, 0,50. 
lado, a última pá de cal no Estado Novo e, por outro, a unidade política entre os intelectuais dos mais diferentes matizes político-partidários.

A política-institucional aparece, então como a preocupação central dos escritores no seu congresso que, sabendo da sua "missão histórica", deram voz ao "povo brasileiro" e lançaram o grito de guerra que o "Brasil" inteiro esperava ouvir:

Os escritores conscientes da sua responsabilidade na interpretação e defesa das aspirações do povo brasileiro, e considerando necessária uma definição do seu pensamento e de sua atitude em relação às questões políticas básicas do Brasil, neste momento histórico, declaram e adotam os seguintes princípios:

Primeiro - A legalidade democrática como garantia da completa liberdade de expressão do pensamento, da liberdade de culto, da segurança contra o temor da violência e do direito a uma existência digna.

Segundo - O sistema de governo eleito pelo povo mediante sufrágio universal, direto e secreto.

Terceiro - Só o pleno exercício da soberania popular em todas as nações, torna possível a paz e a cooperação internacionais, assim como a independência econômica dos povos.

CONCLUSÃO - O Congresso considera urgente necessidade de ajustarse a organização política do Brasil aos princípios aqui enunciados, que são aqueles pelos quais se batem as forças armadas do Brasil e das Nações Unidas. (I CONGRESSO BRASILEIRO DE ESCRITORES, 1945, p. 154-156).

Voltamos à dignidade do escritor e com ela podemos retomar outros dos seus significados. O congresso foi organizado e dirigido, em sua maioria, por escritores que, de alguma maneira, participavam do governo de Vargas, fossem eles considerados oficiais, semi-oficiais ou não-oficiais oficiais. Foi de dentro deste espaço que os escritores se pronunciaram e reafirmaram o papel que estabeleciam para si próprios, em todo caso, legitimando o governo para se auto-legitimar.

No início de 1945, o governo de Vargas já se mostrava como um barco furado. A (re?)democratização institucional já era pensada como inevitável e as transformações já começavam a tomar forma real. Não havia muito a ser feito pelos escritores, a não ser posicionar-se pela democracia se não quisessem sucumbir com o Estado Novo e com a guerra. Era o espaço político-institucional dos escritores que estava em jogo, por isso, esta foi a questão central do congresso e menos a (re?)democratização eminente no país.

Por tudo isto, houve consenso nas propostas que tentavam manter a dignidade do escritor do ponto de vista do prestígio social em relação aos novos meios de comunicação que disputavam o espaço tanto no governo como na opinião pública. Da mesma forma e 
como conseqüência, o consenso nas votações sobre as propostas de emendas à legislação dos direitos autorais buscava ampliar as garantias de prestígio público e proteção legal, significou essa mesma unidade de grupo profissional.

Ao contrário do aparente consenso, a votação da Declaração de Princípios, não publicada por nenhum grande jornal, foi um acordo de bastidores entre as correntes político-partidárias que se encontravam nas direções da entidade.

Agora o leitor pode se livrar de mim e decidir se concorda com a assertiva de Aníbal Machado ao abrir o congresso, com a qual intitulo este texto em forma de pergunta: "É para nos libertar, ou para explorar que escreves? Caminhará isolado o escritor que não encontrar resposta justa a estas interrogações; isolado e alheio às realidades de seu tempo. E ninguém lhe negará o direito de sorrir com desprezo coroando-se a si próprio com as flores de seu jardim secreto. Hamlet acabará Narciso".

\section{Referências}

AMADO, Jorge. Navegação de cabotagem, Rio de Janeiro, Editora Record, 1992

CANÇADO, José Maria. Os sapatos de orfeu. São Paulo: Scritta, 1991.

Correio da Manhã, 1944

Declaração de Princípios. Diretrizes, Rio de Janeiro, n. 102, junho de 1942.

DULLES, John F. Dulles. O comunismo no Brasil. Rio de Janeiro: Nova Fronteira, 1985.

FUNDO AGÊNCIA NACIONAL. (Série Administração). [DG-512].

FUNDO ASTROJILDO PEREIRA. Coleção fotográfica. ASMOB: CEDEM: UNESP,

FUNDO Gabinete Civil da Presidência da República/AN. (Série: Ministério da Educação e Saúde Pública/Departamento de Educação).

GATTAI, Zélia. Um chapéu para viagem. Rio de Janeiro: Record, 1982.

GOMES, Ângela M. de C. História e historiadores: política cultural no Estado Novo. Rio de Janeiro: Fundação Getúlio Vargas, 1998.

GOULART, Silvana. Sob a verdade oficial: ideologia, propaganda e censura no Estado Novo. São Paulo: Marco Zero, 1990. 


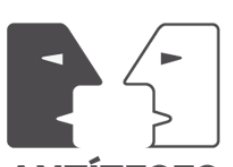

ANTÍTESES

HAUSSEN, Dóris Fagundes Haussen. Rádio e política. Porto Alegre: Edipucrs, 1997.

LAHUERTA, Milton. Elitismo, autonomia, populismo: os intelectuais na transição dos anos 40. 1992. Dissertação (Mestrado em Ciência Política) - Instituto de Filosofia e Ciências Humanas, Universidade Estadual de Campinas, Campinas.

LENHARO, Alcir. Estado Novo, Estado Velho: novas direções historiográficas. In: MUSEU PAULISTA, São Paulo, 1986. Anais... São Paulo: Editora, 1986.

LOTTMAN, Herbert Lottman. A Rive Gauche: escritores, artistas e políticos em Paris: 1930 a 1950. Rio de Janeiro: Guanabara, 1987.

Manifesto de 1942. Literatura, Rio de Janeiro, n. 4, junho de 1947.

MILLIET, Sérgio. Discurso de abertura. In: CONGRESSO BRASILEIRO DE ESCRITORES, 1., 1945, São Paulo. Anais... São Paulo: ABDE, 1945.

MOTTA, Carlos Guilherme. Ideologia da cultura brasileira (1933-1974). São Paulo: Editora Ática, 1994

O Estado de São Paulo, 1945 